\title{
Arnau de Vilanova i la concepció de la medicina com a ciència aristotèlica Sergi Grau Torras
}

A partir del segle XIII, les principals universitats europees comencen a implementar una nova pràctica mèdica fonamentada en la filosofia natural d'Aristòtil (Siraisi 1981: 186-201; García Ballester 1995). Això fou la conseqüència del desenvolupament de la filosofia natural a les escoles d'arts, preparatòries per als estudis superiors de teologia, dret i medicina, i de la repercussió de diverses consideracions de la filosofia natural sobre aspectes mèdics: per exemple, els principis fonamentals de la matèria, els principis de mutació en els cossos, l'estudi de la fisiologia i l'anatomia animal, el concepte de l'humit radical. Aquesta situació va desencadenar debats entre els metges $i$ els filòsofs de la natura que posaven de relleu les semblances $\mathrm{i}$ les divergències entre les dues disciplines i, més concretament, entre el metge Galè i el filòsof Aristòtil. A més, la filosofia natural va permetre instaurar la base del coneixement teòric de la natura en l'àmbit mèdic i, alhora, desenvolupar la medicina com una ciència en el sentit aristotèlic.

Arnau de Vilanova és un cas representatiu d'aquesta nova pràctica mèdica fonamentada en la filosofia natural. Va estudiar a la Facultat de Medicina a Montpeller cap a la dècada de 1260, quan la gran majoria de les obres d'Aristòtil estaven sent traduïdes al llatí i diverses de les seves consideracions eren emprades en les obres mè- diques que servien per explicar i complementar el currículum acadèmic. El 1290, quan Arnau va tornar a la Facultat de Medicina a Montpeller per exercir-hi la docència, va ser el moment en què va escriure les principals obres mèdiques. En aquests volums escrits en llatí, i destinats a un públic especialitzat i als seus alumnes, Arnau de Vilanova va emprar un gran ventall d'obres aristotèliques i va intervenir en les discussions de l'època entre les consideracions de Galè i d'Aristòtil. Hi va escriure sobre la naturalesa de la medicina, l'ús de la filosofia natural en la pràctica mèdica i va establir la seva concepció de la medicina com a ciència aristotèlica.

\section{La medicina es divideix en dues parts: una teòrica i una pràctica}

La consolidació de l'estudi de les obres d'Aristòtil a les facultats d'arts va permetre als estudiants de medicina adquirir una sòlida formació teòrica en filosofia natural. Això va facilitar que, amb el temps, els metges comencessin a dotar la medicina d'un contingut teòric o filosòfic, que abans no existia, i definissin la naturalesa de la seva tasca com a coneixement, és a dir, com una scientia aristotèlica que derivava dels principis de les causes universals als efectes específics.

Aristòtil tracta del concepte de ciència ex- 
perimental i del mètode científic en els Analytica posteriora. Aquí, Aristòtil hi estableix les pautes de la ciència demostrativa i la certesa de les premisses científiques a través del sil-logisme; l'activitat científica, per tant, es refereix a un hàbit intellectual mitjançant el qual ens predisposem a acceptar unes conclusions que són vertaderes i certes perquè deriven d'una demostració sillogística dels principis universals (Serene 1982: 497-517; Lohr 2004: 251-269).

A partir del vincle de la medicina amb la filosofia natural, i més concretament amb les ciències especulatives, els metges van reflexionar sobre la noció de medicina com a ciència aristotèlica. Els primers testimonis que aborden aquesta qüestió sorgeixen a principis del segle XII en l'àmbit de l'escola de medicina de Salern. La traducció llatina de la Isagoge de Johannitus, un dels primers tractats àrabs traduits al llatí que es va configurar com una de les obres cabdals del

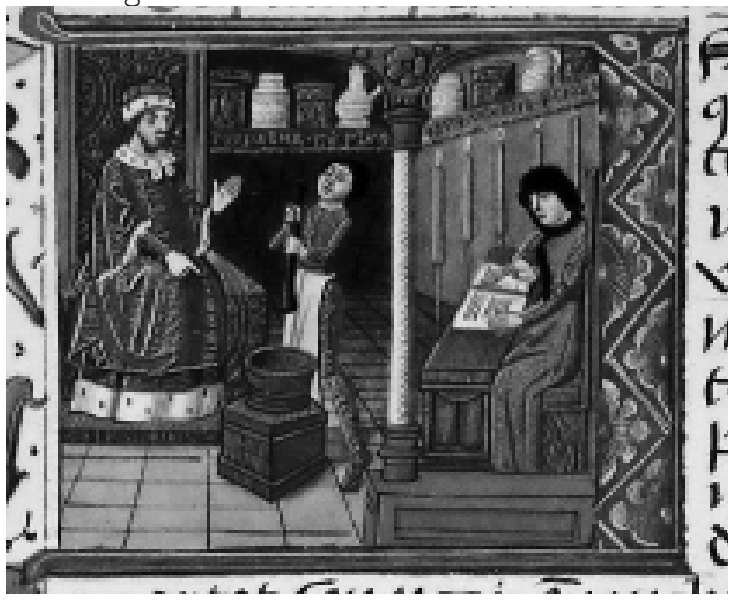

Galè instruint des de la càtedra mentre un escrivà anota les fórmules en un manuscrit del Liber cathagenarum destruït al bombardeig de Dresden (Wellcome Library, London, Wellcome Images, Loo25921)

currículum mèdic, afirmava al pròleg que «la medicina es divideix en dues parts, una teòrica i una pràctica» (Maurach 1978:151,§1). Després de la seva traducció, en les introduccions i els comentaris, els metges de Salern van posar èmfasi en

1 Aristòtil, Analytica priora, I.1, 24a-25a. Les citacions a l'obra d'Aristòtil que proporcionem utilitzen, com és comú, la numeració de l'edició d'Immanuel Bekker, en què s'indica la pàgina, la columna i la línia del text. Les edicions llatines de l'obra d'Aristòtil es poden trobar a la base de dades Aristoteles Latinus database. la vessant teòrica de la medicina alhora que van subordinar la pràctica a la teoria; amb això, van dotar la disciplina mèdica del caràcter de ciència sota els paràmetres aristotèlics, tot establint la medicina com a branca de la física (Kristeller 1976: 57-87; Jordan 1987: 137-145).

En poc temps, aquesta qüestió va convertir-se en un tòpic de discussió ineludible per als metges, sobretot quan Avicenna va abordar-la en el primer llibre del seu Cànon de la medicina (Jacquart 2002: 321-324). Avicenna defineix la medicina com la ciència del cos humà en tant que aquest és sanable; la medicina, per tant, està en relació a les seves disposicions de salut i malaltia, i a l'estat per a recuperar la salut. ${ }^{2}$ Avicenna estipula que la medicina es divideix entre una teoria $\mathrm{i}$ una pràctica, i totes dues divisions de la medicina formen part de la ciència: una és la ciència que estudia els principis de la medicina i l'altra brega amb la forma de posar en pràctica aquests principis. Tanmateix, aquesta part pràctica no només està relacionada amb la realització de la tasca pròpia del metge sinó que fa referència a aquella branca del coneixement mèdic que, una vegada adquirida, permet al metge de formar-se un judici que està directament relacionat amb executar el tractament. Aquesta qüestió és important en la mesura que Avicenna estableix l'estatus de ciència demostrativa a la disciplina mèdica pel recurs del concepte de scientia aristotèlica, ja sigui la part teòrica com la pràctica. La seva consideració tindrà repercussió en metges posteriors, com per exemple, Arnau de Vilanova.

Arnau aborda aquesta qüestió en diverses obres mèdiques. En una de les seves últimes grans obres de medicina teòrica, I'Speculum medicinae, finalitzada a finals de 1308 o a principis de 1309, ofereix una completa reflexió al respecte. Defineix la medicina com la ciència que té per objecte conèixer les disposicions del cos humà com a cos sanable, així com la conservació de la salut o la seva recuperació quan l'ha perduda. ${ }^{3}$ Arnau estableix que la medicina consta d'una part teòrica i d'una altra de pràctica: la medici-

2 Avicenna, Liber canonis, llibre 1, cap. 1.

3 Arnau de Vilanova, Speculum medicinæ, f. 1ra. Fem servir com a referència l'edició de l'obra dins d'Arnau de Vilanova 1532. 
na teòrica té per objecte d'estudi les disposicions del cos sanable en la mesura que és necessari per la seva tasca, i la medicina pràctica aplica aquestes disposicions en el cos del pacient. ${ }^{4}$

Sota aquesta pauta, Arnau diferencia entre una disposició natural (la salut) i una disposició contrària a la salut (la malaltia). També estipula que les disposicions del cos sanable es divideixen en les coses naturals, les no naturals i les coses contràries a la natura. A la vegada, la medicina teòrica es divideix en tres parts: fisiologia, higiene i terapèutica, i patologia; la fisiologia estudia les 'coses naturals' (els elements, les complexions, els humors, els membres, les virtuts, les operacions i els esperits); la higiene i la terapèutica examinen les 'sis coses no naturals', és a dir, aquells elements que poden afectar la salut de manera positiva o negativa (l'aire, l'exercici, la dieta, el descans i el son, les emocions i l'evacuació de residus) i finalment, la patologia analitza les coses contràries a la natura que coneixem com a malaltia. ${ }^{5}$ Aquesta concepció teòrica de la medicina havia de prevaler, alhora, amb aquella que entenia la medicina com un art o una tècnica, en el qual la pràctica també tenia un pes important en la producció de coneixement.

\section{La medicina és una ciència o un art?}

Quan els metges aborden la qüestió de la naturalesa de la medicina també presenten la relació entre les dues parts, la teòrica i la pràctica. Això desencadena una discussió que encara perdura avui dia sobre si la medicina és una ciència o un art. Mentre que el concepte de scientia es pot traduir com a 'ciència' només en el sentit que significa coneixement empíric a partir de la deducció, el concepte d'ars segons la concepció aristotèlica es pot entendre com la tècnica en el sentit d'habilitat que s'aprèn a través de l'experiència o com la capacitat humana per a produir a través de l'acció.

Aquesta accepció del terme és molt diferent de la que avui dia donem a aquest concepte; mentre que el terme ciència ha mantingut el seu

4 Arnau de Vilanova, Speculum medicinæ, ff. 1ra-b. 5 Arnau de Vilanova, Speculum medicinæ, f. 1 rb.

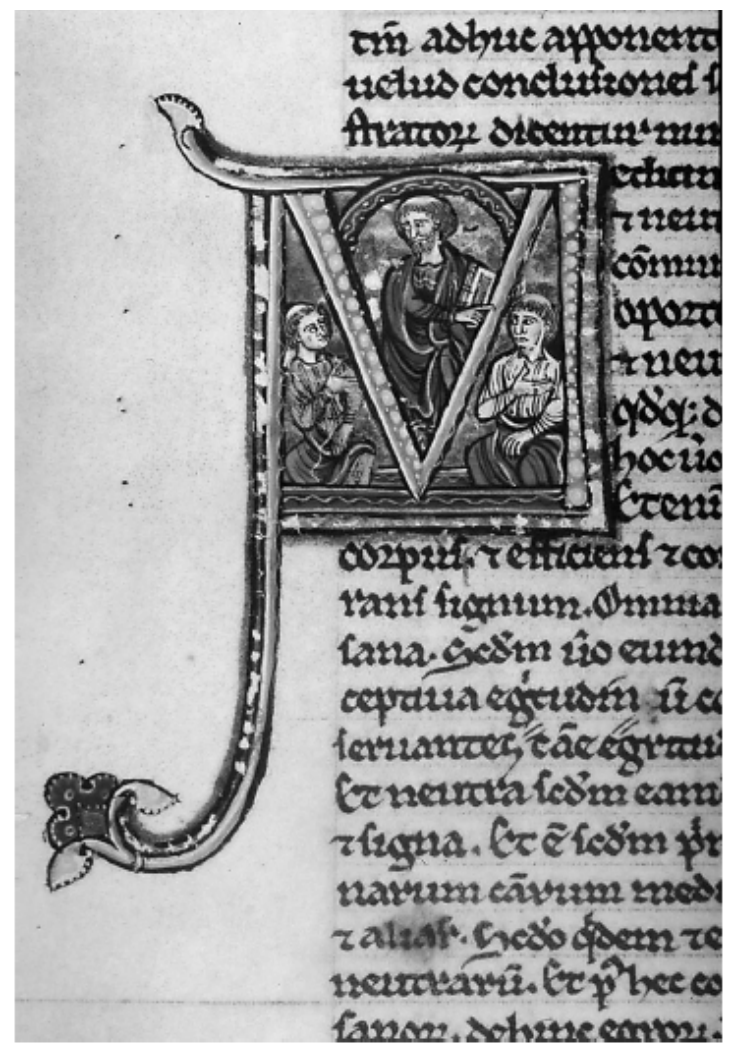

Un mestre de medicina mostra un llibre a un estudiant en una caplletra de la Isagogue de Joanici copiada a Oxford al segle XIII (National Llibrary of Medicine, ms 78, f. 61v).

caràcter i fa referència a allò que forma part del mètode científic, el terme art es refereix a les arts visuals, a l'estètica i a la creació artística, un concepte allunyat de la producció de coneixement científic. Per tant, quan considerem la medicina com un art és sota l'accepció aristotèlica del terme, en la mesura que la professió exercida en el tractament dels pacients - amb el coneixement mèdic, les accions, les habilitats i la intuïció del metge, un element molt important- tenen un paper fonamental en la producció de coneixement.

Arnau de Vilanova aborda aquesta qüestió en el Tractatus de intentione medicorum, una de les primers obres que va escriure durant el seu període de docència a Montpeller. El tractat té l'objectiu de resoldre el problema de les contradiccions entre les autoritats i alhora definir els límits de la certesa mèdica i l'ús que el metge ha de fer de la filosofia natural. Aquí, Arnau de Vilanova posa les bases de la seva epistemologia mèdica en plantejar-se el debat sobre si la medicina és 


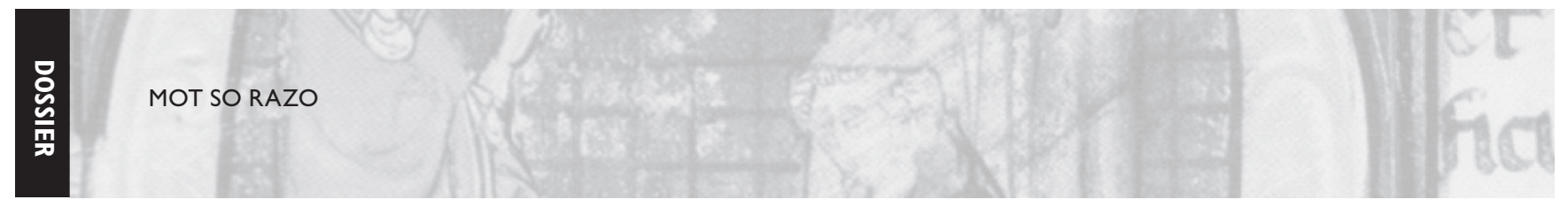

una ciència (scientia) o una tècnica (ars); la medicina és per a Arnau una scientia que es fonamenta en la natura, i la filosofia natural aristotèlica és l'eina per a conèixer aquesta natura; ara bé, en quina mesura el metge ha de conèixer la filosofia natural?

Per respondre a aquesta qüestió, en aquesta obra Arnau exposa les diferències entre els objectius del metge i els del filòsof natural. Arnau considera que el metge és un tècnic pràctic que es guia pels sentits i per aquesta raó, només s'ha de centrar en els elements de la filosofia natural que li serveixin per a la seva tasca. Així, doncs, la intenció del metge és la d'ordenar cap a un únic fi la custòdia de la disposició natural en el cos humà, anomenada salut (o temperament natural). El contrari d'aquesta disposició, la malaltia, s'esforça per a treure la disposició natural del cos. El metge, per tant, orienta el seu coneixement i teorització cap a la pràctica, i per això, segons Arnau, el metge no està interessat a entendre més teoria (o filosofia natural) que la necessària perquè regeixi la seva pràctica. $^{6}$

La concepció arnaldiana de la medicina com un art té la seva ressonància en la visió de la medicina que ofereix Aristòtil en la seva Ethica (McVaugh 2000: 27). En aquesta obra, Aristòtil estableix la distinció entre la ciència, definida com un mètode demostratiu, i l'art, que defineix com un mode productiu (o disposició productiva) acompanyat de la raó vertadera? Les arts, per tant, es destinen a formes de coneixement pràctic, i el seu concepte d'art està vinculat amb el

6 Arnau de Vilanova, Tractatus de intentione medicorum, p. 101, lín. 8-10.

7 Aristòtil, Ethica, VI.4, 1140a-b. procés de produir. Un dels exemples que ofereix Aristòtil per illustrar la seva visió de l'art és el de la medicina i la pràctica mèdica.

Aristòtil presenta la medicina com un model metodològic per a l'ètica, ja que la medicina constitueix el prototip d'una combinació entre teoria i pràctica diària (Jaeger 1957: 59-60; Lloyd 1968: 68). Per Aristòtil, la medicina, i per tant l'ètica, brega amb situacions individuals i per aquesta raó no només s'ha de conèixer la veritat com una regla general sinó també saber actuar en casos individuals, igual que en la medicina s'ha de conèixer el tractament individual de cada pacient. Aristòtil utilitza l'exemple de la medicina com a model d'anàlisi teòrica de l'ètica i alhora per la seva aplicació pràctica en la vida humana i l'educació.

D'aquesta manera, Aristòtil estipula que el metge ha de conèixer primer els principis universals, els quals són necessaris per a guarir una malaltia $\mathrm{O}$, en aquest cas, tractar millor el pacient, i després ha de saber-los aplicar en casos particulars. ${ }^{8}$ Un exemple d'això el trobem quan Aristòtil afirma que els metges no es formen només a través dels treballs (o llibres) de medicina, encara que aquests siguin de pràctica i introdueixin l'estudiant en el tractament i en les disposicions naturals; aquests llibres només són d'utilitat a aquells que tenen l'experiència adequada i, en canvi, són inútils als qui no coneixen la ciència mèdica. ${ }^{9}$ Aquesta idea és la que fonamenta la concepció arnaldiana de la medicina; de fet, en l'exposició d'Arnau hi constatem allò que Michael McVaugh ha descrit com «l'instrumentalisme

8 Aristòtil, Ethica, $\mathrm{X}_{9}, 1180 \mathrm{~b}_{20}$.

9 Aristòtil, Ethica, X.9, 1181b2-6. 
mèdic», el qual porta Arnau a entendre que tota teoria és un instrument per a l'acció i la transformació de l'experiència (McVaugh 1990: 75-84; McVaugh 2000: 145-147).

La concepció mèdica d'Arnau fou compartida per diversos metges amb una reflexió similar. Un dels casos que més s'aproxima és el metge italià Pietro d'Abano quan afirma en el Conciliator differentiarum philosophorum et precipue medicorum que «la finalitat de la medicina no és la veritat sinó l'operaciós.10 Pietro d'Abano, un metge establert a Pàdua després d'estudiar medicina a París que també integra la filosofia natural en la medicina i s'esforça en conciliar les dues disciplines, presenta la medicina no només com un art sinó també com una ciència aristotèlica. En aquest cas, Pietro d'Abano uneix els conceptes de teoria i de pràctica a través de l'intellecte humà, com una facultat especulativa, d'una banda, i pràctica de l'altra, alhora que unifica la facultat intellectual del coneixement amb la de la producció (Federici 1999: 227-255; Turetta 2008: 659-731). Així, doncs, Pietro d'Abano especifica dues virtuts necessàries per als metges: el coneixement a través dels llibres dels principis universals, i el coneixement adquirit per l'observació de l'acció dels medicaments en els cossos particulars; la medicina és, en definitiva, un art que opera.

\section{Entre la filosofia natural i l'uars» mèdica}

A finals del segle XIII, el món mèdic va conèixer la traducció llatina del Kitab al-kulliyat d'Averrois, coneguda al món llatí com el Colliget. La seva arribada als ambients acadèmics va portar a una reformulació de la relació entre la teoria i la pràctica mèdica (Jacquart 2008: 40). De fet, tota aquesta reflexió que hem vist, i l'èmfasi d'alguns metges en el concepte d'art en medicina, no es pot entendre sense tenir en consideració l'impacte de les idees d'Averrois en aquest domini. L'entrada del Colliget en la discussió va propiciar un nou punt de vista epistemològic en definir la medicina com un art operatori fonamentat sobre els principis vertaders, els quals no es poden desvincular

10 Pietro d'Abano, Conciliator controversiarum, quæ inter philosophos et medicos versantur, ff. $5 \mathrm{va}-8 \mathrm{r}$. d'aquells que exposa la filosofia; Averrois presenta, en definitiva, la subordinació de la medicina a la filosofia de la natura."

Averrois exposa en el Colliget que la medicina és un art fonamentat, d'una banda, en l'especulació, que és ciència natural, i, de l'altra, en la pràctica, relacionada amb la medicina experimental i l'art de l'anatomia.12 Averrois accepta que aquesta pràctica dóna certa autonomia a la disciplina, perquè no es pot deduir tot de la teoria, sinó que també es nodreix de l'experiència i del coneixement personal. Per aquesta raó, Averrois distingeix dos tipus de coneixement en medicina: l'especulatiu (o teòric) i el pràctic. Ara bé, mentre que la filosofia natural abraça els principis d'aquest art a través de l'especulació, «l'artista» ha d'extreure les normes del seu art de l'experiència, i d'aquí aprèn com aplicar diferents medicines en concret. Tot i la importància de la pràctica, en definitiva, Averrois supedita el seu coneixement al de la filosofia.

Després de la seva formulació, no és estrany, doncs, les consideracions d'alguns metges; de fet, Arnau de Vilanova escriu sobre aquest assumpte a principis de la dècada dels anys noranta del segle XIII, tot just quan s'ha difós la traducció llatina del Colliget en els ambients universitaris. Per Arnau, com molts altres metges de la seva època, com Pietro d'Abano, no es pot dissociar la part teòrica de la pràctica, la part de la ciència i la de l'art. Arnau de Vilanova era un metge més racionalista que empirista i per aquesta raó dedica esforços a la cerca d'un procediment racional que ajudi a conservar o adquirir la salut. Per exemple, en el De consideratione operis medicinæ, una obra redactada a principis de la dècada de 1290, on exposa la doctrina de la indicació terapèutica de Galè en l'aspecte pràctic, Arnau adverteix dels perills que el metge utilitzi un mètode massa empíric en la seva tasca, atès que aquest ha de defugir rutines i teràpies aplicades mecànicament, i ha d'actuar racionalment segons les circumstàncies del pacient. La seva forma d'entendre la medicina, sobretot a partir de l'instrumentalisme mèdic,

11 Averrois, Colliget libri VII, I, 1, f. 5 ra.

12 Averrois, Colliget libri VII, I, 1, f. 5 rb. 


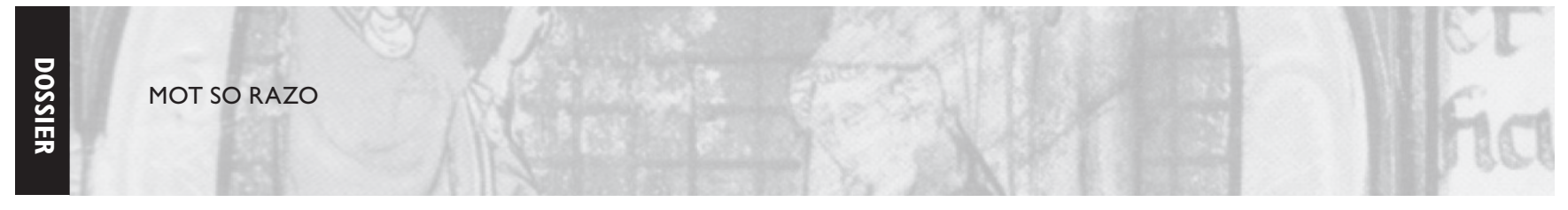

allunyava la medicina de l'especulació teòrica, i per tant, de la visió averroista.

En una altra obra on Arnau comenta el primer aforisme d'Hipòcrates, la Repetitio super Vita brevis, escrita la primavera de 1301, explica per què l'art de la medicina és llarg en termes absoluts (McVaugh \& Salmón 2014: 128-130). Arnau exposa que, en un sentit, s'entén de manera estricta com la regla rectora d'una certa acció envers un $\mathrm{fi}$, mentre que en l'altre, s'entén de manera àmplia com una collecció de preceptes encaminats a un sol fi; així ho entenen Hipòcrates i Galè quan afirmen que l'art és llarg a causa del gran nombre de preceptes per a una bona pràctica.13 Per aquesta raó, l'art mèdic agrupa un nombre cada vegada més elevat d'observacions i de preceptes que serveixen per a formar enunciats generals, és a dir, veritats fixades. És per això que Arnau, com afirma Aristòtil en la Metaphysica, defensa que l'experiència crea l'art.14

Així, doncs, en la medicina, Arnau sosté que podem apropar-nos a unes veritats que s'acumulen en un cos creixent de literatura mèdica, tot i que encara hi hagi qüestions irresoltes que poden ser objecte de discussions. ${ }^{15}$ Aquests preceptes o normes per a la bona pràctica es construeixen a partir de l'experiència del metge que aprèn en situacions concretes i amb l'aplicació de medecines diferents a subjectes que tenen malalties diferents; però la variabilitat de tots aquests elements garanteix que fins i tot un sol precepte general sigui difícil d'obtenir. Arnau atorga una importància cabdal a l'experiència pràctica del metge per a formar les normes, i amb això, posa en relleu la importància de la praxi mèdica per establir coneixements. En aquest sentit, Arnau, com Avicenna, dota la part pràctica, com la teòrica, del caràcter de ciència.

En una altra obra sobre la pràctica mèdica que Arnau va deixar inacabada, el De parte operativa, també dedica unes quantes línies a definir

13 Arnau de Vilanova, Repetitio super Vita brevis, p. 205, lín. 413-424.

14 Arnau de Vilanova, Repetitio super Vita brevis, p. 214, lín. 717-722; aquí, Arnau de Vilanova fa referència a Aristòtil, Metaphysica, 981a5.

15 Arnau de Vilanova, Repetitio super Vita brevis, p. 209, lín. 571-572. la naturalesa de la medicina. En aquest cas, Arnau afirma novament que la salut és el propòsit del metge i l'objectiu de la medicina.16 Seguint amb coherència la seva argumentació de les obres prèvies, també afirma que el metge o ministre de la naturalesa opera per l'art. Aquí constatem novament la influència d'Aristòtil en la seva concepció de l'ars mèdica en tant que l'artista treballa el cos humà i opera amb l'art de la medicina. Aristòtil aborda en la Metaphysica la producció espontània amb relació als processos de producció artística i natural, i conclou que la forma preexisteix sempre; determinades coses no arriben a existir si no actua aquell qui posseeix art, com per exemple la salut, i en canvi altres sí.7 L'origen de la producció de l'art està en el coneixement d'allò que es produeix, en aquest cas la salut. Arnau exposa aquesta idea en presentar el símil de l'art de la medicina amb l'art de l'agricultura perquè, com l'agricultura, la medicina pot ajudar la natura a expressar millor el que veritablement hi ha en la natura. ${ }^{18}$

\section{Conclusions}

Arnau se situa, en definitiva, en contra de la submissió de la medicina a la filosofia de la natura que propugna Averrois. Per aquesta raó, la concepció de l'art té un pes important en la medicina arnaldiana. Aquesta idea la desenvolupa extensament a principis de la dècada de $1290 \mathrm{amb}$ el Tractatus de intentione medicorum, una obra que presenta la seva gran reflexió al respecte. Amb el pas del temps, Arnau es va mantenir ferm en la seva concepció de la medicina; gairebé vint anys després, en l'etapa final de la seva carrera, Arnau retorna a la idea de l'artífex en I'Speculum medicinæ $i$ en el De parte operativa amb la mateixa lògica que havia establert en la primera obra. Així, doncs, l'Ethica i la Metaphysica d'Aristòtil van tenir un paper rellevant en la seva formulació sobre la naturalesa de la medicina.

\footnotetext{
16 Arnau de Vilanova, De parte operativa, f. 123ra. Fem servir com a referència l'edició de l'obra dins d'Arnau de Vilanova 1532.

17 Aristòtil, Metaphysica, 1034a9-b7.

18 Arnau de Vilanova, De parte operativa, f. 123 ra.
} 


\section{Obres mèdiques}

ARNAU DE VILANOVA 1532: Medici acutissimi, Opera nuperrime revisa, una cum ipsius vita recenter hic apposita, Lió: Jacques Myt per a Scipion de Gabiano.

Averrois, 1553, Auerrois Cordubensis Colliget libri VII: cum quibus etiam nunc primum in quinto libro impressimus translationem, Venècia: apud Juntas.

AvICENNA, 1507: Liber canonis Avicenne: revisus \& ab omni errore mendaque purgatus summaque cum diligentia impressus, translatus a Bernardo Cremonensis ab arabico in latinum, Venècia: Paganini.

Pietro d'Abano, 1565: Conciliator controversiarum, quæ inter philosophos et medicos versantur, Venècia: apud Juntas.

McVaugh, M. R. 2000 (ed.): Arnau de Vilanova, Tractatus de intentione medicorum, Barcelona: Universitat de Barcelona-Fundació Noguera.

McVaugh, M. R. 2014 (ed.): Arnau de Vilanova, Expositio super aphorismo Hippocratis «ln morbis minus»); Repetitio super aphorismo Hippocratis "Vita brevis»); estudi a cura de $M$. R. McVaugh i F. Salmón, Barcelona: Fundació Noguera-Universitat de Barcelona.

\section{Edició llatina d'Aristòtil}

Aristoteles Latinus Database (ALD1), ed. J. Brams, P. Tombeur, Turnhout: Brepols, 2003 [http://www.brepolis.net].

\section{Estudis}

Federici VescovinI, Graziella, 1999: «La médecine, synthèse d'art et de science selon Pierre d'Abano», Les doctrines de la science de l'antiquité à l'âge classique, ed. Roshdi Rashed i Joël Biard, Lovaina: Peeters, 227-255.
García Ballester, Luis 1995: «The Construction of a New Form of Learning and Practicing Medicine in Medieval Latin Europe», Science in context, 8, 75-102.

JAEGER, Werner, 1957: «Aristotle's use of Medicine as Model of Method in His Ethics», The Journal of Hellenic Studies, 77/1, 54-61.

JACQUART, Danielle, 2008: «La médecine entre théorie et pratique: retour sur quelques définitions originelles»», Handlung und Wissenschaft, Die Epistemologie der praktischen Wissenschaften im 13. Und 14. Jahrhundert, ed. M. Lutz-Bachmann i A. Fidora, Berlín: Akademie Verlag, $33-42$.

JACQUART, Danielle, 2002: «Lectures universitaires du Canon d'Avicenne», Avicenna and his Heritage, ed. J. Janssens i D. de Smet, Lovaina: Leuven University Press, 313-324.

Jordan, Mark D., 1987: «Medicine as a Science in the Early Commentaries on Johannitius»», Traditio, 43, 121-145.

Kristeller, Paul Oskar, 1976: «Bartholomaeus, Musandinus and Maurus of Salerno and other early commentators of the Articella, with a tentative list of texts and manuscripts»», Italia Medioevale e Umanistica, 19, 57-87.

LLOYD, G. E. R., 1968: «The Role of Medical and Biological Analogies in Aristotle's Ethics»), Phronesis, 13/1, 68-83.

LOHR, Charles H., 2004: «Aristotelian 'Scientia', the 'Artes', and English Philosophy in the $14^{\text {th }}$ Century $)$, Erkenntnis und Wissenschaft. Probleme der Epistemologie in der Philosophie des Mittelalters, ed. M. LutzBachmann, A. Fidora i P. Antolic, Berlín: Akademie Verlag, 265-274.
MAURACH, Gregor, 1978: «Johannicius: Isagoge ad techne Galieni»», Sudhofs Arhiv, 62, 148-174.

McVaugh, Michael R., 1990: «The Nature and Limits of Medical Certitude at Early FourteenthCentury Montpellier»», Osiris, 6, $62-84$.

McVaugh, Michael R. \& Salmón, Fernando, 2014: «Introducció», a McVaugh, 2014: 107-179.

Serene, Eileen, 1982: «Demonstrative Science», The Cambridge History of Later Medieval Philosophy. From the Rediscovery of Aristotle to the Disintegration of Scholasticism, 1100-1600, ed. N. Kretzmann et al., 497-517.

SIRAISI, Nancy G., 1981: Taddeo Alderotti and His Pupils: Two Generations of Italian Medical Learning, ca. 1265-1325, Princeton: Princeton University Press.

TURETTA, Laura, 2008: «Bibliografia delle opere a stampa di e su Pietro D'Abano», Convegno internazionale per il 750 anniversario della nascita di Pietro D’Abano: Abano Terme, Sala Kursaal, venerdi zo novembre-sabato 1 dicembre 2007, Roma: Dipartimento di Medicina sperimentale-sezione di Storia della medicina, 659-731. 


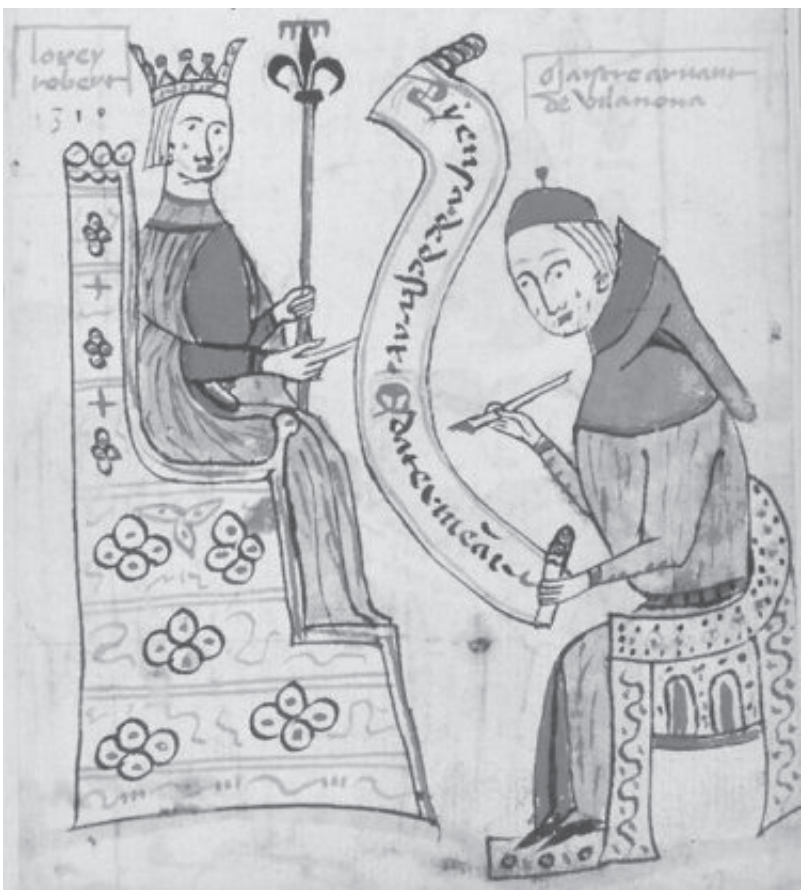

Robert de Nàpols dicta el tractat d'agronomia de Bertran Boisset a Arnau de Vilanova (Carpentràs, Bibliothèque Inguimbertine, ms. 327, detall). 